\title{
KETERPAKAIAN DATABASE ONLINE: STUDI KASUS LAYANAN E-JOURNAL 2007-2010 DI PERPUSTAKAAN UGM
}

\author{
Oleh: Maryono
}

\section{Abstract}

The usage statistics of online databases need to be studied from various aspects, all of which are useful for optimizing the use of the e-journal. This case study examines the ejournal service statistics 2007-2010, as well as its usage growth through the use of booking service of ejournal article at Gadjah Mada University Library. Ebsco is an online database of the most needed, followed by Proquest, JSTOR, Springer, and ScienceDirect. Also found that most users ordering ejournal prefer to come straight away, although it's provided messaging and e-mail services.

Keywords: e-journal, ebsco, proquest, sciencedirect, springer, library statistics

*) Pustakawan UGM

\section{LATAR BELAKANG}

.Penyediaan literatur e-journal melalui database online mengalami pertumbuhan sangat pesat seiring dengan kemudahan akses melalui inovasi teknologi yang diterapkan. Perguruan tinggi pada umumnya telah mulai merintis penggunaan e-journal dengan melanggan sesuai kebutuhan program studi yang diselenggarakan. Ketersediaan free $e$ journal di internet kini juga menjadi sumber literatur e-journal yang sangat besar. Meskipun telah banyak terjadi peralihan dari bentuk tercetak ke bentuk elektronik yang memiliki banyak fitur kemudahan, tetapi ternyata pemakaian jurnal dan e-journal masih sangat rendah atau belum sesuai dengan yang diharapkan. Penelitian oleh Purnomowati (2001 : 10) dan Andriaty (2005:28) membuktikan hal tersebut.

Untuk melanggan database online membutuhkan biaya yang cukup besar. Dengan melanggan database online akan memperoleh hak akses dalam jangka waktu tertentu, tetapi tidak mempunyai hak memiliki secara fisik. Persoalan kepemilikan sering dipermasalahkan. Demikian juga kesesuaian antara biaya dan keterpakaiannya sering dipertanyakan. Oleh karena itu diperlukan kesadaran akan manfaat e-journal yang pada saatnya nanti akan menumbuhkan minat untuk memakai literatur artikel e-journal.

\section{A. Rumusan Masalah}

1. Bagaimanakah pertumbuhan pemakaian layanan e-journal?

2. Bagaimanakah pertumbuhan komposisi pemakai layanan e-journal?

3. Bagaimanakah pertumbuhan penggunaan media pemesanan $e$ journal?

4. Bagaimanakah pertumbuhan jumlah $e$ journal yang dipesan dan belum tersedia?

5. Bagaimanakah pertumbuhan pemakai masing-masing database e-journal?

\section{B. Tujuan Penelitian}

1. Untuk mengetahui pertumbuhan pemakaian layanan e-journal

2. Untuk mengetahui pertumbuhan komposisi pemakai layanan e-journal

3. Untuk mengetahui pertumbuhan penggunaan media pemesanan $e$ journal

4. Untuk mengetahui pertumbuhan jumlah e-journal yang dipesan dan belum tersedia

5. Untuk mengetahui pertumbuhan pemakai masing-masing database ejournal 


\section{Manfaat Penelitian}

Manfaat penelitian ini adalah untuk mengetahui pertumbuhan dan keterpakaian . layanan e-journal sehingga dapat memenuhi kebutuhan informasi secara cepat dan tepat. Selain itu dapat mengembangkan ilmu dan pengetahuan yang berhubungan dengan pendayagunaan sumber-sumber informasi terkini.

\section{PENELITIAN TERDAHULU}

Penelitian tentang pemakaian e-journal di kalangan peneliti pernah dilakukan oleh Ali dan Faizul (2011). Mereka menggunakan survei untuk mengetahui tingkat pemakaian ejournal, dan menemukan fakta bahwa $60 \%$ peneliti di Universitas Delhi telah memakai e-journal setiap minggunya, $50 \%$ setiap hari, $9 \%$ setiap bulan, dan hanya $4 \%$ yang jarang memakainya. Temuan lainnya bahwa pemakaian e-journal terutama : untuk keperluan mendukung riset sebanyak 56\%, 31\% untuk melengkapi naskah seminar dan presentasi, $25 \%$ untuk mendukung studi, $19 \%$ untuk menerbitkan buku dan artikel jurnal, dan $12 \%$ untuk mendukung pengembangan spesialisasi masing-masing peneliti. Andriaty (2005:28) dalam penelitiannya menemukan bahwa para peneliti bidang pertanian, belum banyak memanfaatkan jurnal elektronik, sehingga berpengaruh terhadap kemutakhiran artikel yang disitir, dan bahwa $91,42 \%$ artikel yang disitir berusia lebih dari 2 tahun. Kondisi tersebut disebabkan belum tersedianya fasilitas yang memadai untuk mengakses informasi elektronik.

Dalam sebuah penelitian survei, Ilo dkk (2010:5) menemukan fakta bahwa e-journal merupakan jenis literatur yang paling banyak digunakan untuk mendukung riset tugas akhir mahasiswa, yaitu sebanyak $36,9 \%$, disusul $e$ book $24,1 \%$, surat kabar dan majalah online $14,9 \%$, laporan proyek $11,3 \%$, dan diktat kuliah $9,9 \%$. Berdasarkan penelusuran yang peneliti lakukan, belum pernah didapatkan penelitian yang membahas karakteristik e-journal dan pertumbuhan pemakaiannya, sehingga peneliti memilih untuk mengangkat persoalan tersebut ke dalam sebuah studi kasus.

\section{LANDASAN TEORI}

Dalam Buku Pedoman Perpustakaan Perguruan Tinggi (2005:43), disebutkan bahwa kebijakan pengembangan koleksi didasari asas sebagai berikut:

1. Kerelevanan, koleksi hendaknya relevan dengan program pendidikan, pengajaran, penelitian, dan pengabdian pada masyarakat.

2. Berorientasi kepada kebutuhan pengguna, meliputi tenaga pengajar, peneliti, administrasi, mahasiswa, dan alumni.

3. Kelengkapan, bukan hanya buku ajar, tetapi juga bidang ilmu yang berkaitan dengan program yang ada.

4. Kemutakhiran, perpustakaan harus mengadakan dan memperbaharui bahan perpustakaan sesuai dengan perkembangan ilmu pengetahuan.

5. Kerja sama, koleksi hendaknya merupakan hasil kerja sama semua pihak yang berkepentingan, yaitu antara pustakawan, tenaga pengajar, dan mahasiswa, sehingga dengan kerja sama tersebut diharapkan pengembangan koleksi dapat berdaya guna dan berhasil guna.

Kemutakhiran merupakan karakteristik jurnal yang sangat dibutuhkan pemakai, di antaranya yang dikemukakan oleh Prawati (2003 : 1) serta Kusmayadi dan Rushendi (2007:6). Karakteristik tersebut bermanfaat untuk meningkatkan kualitas penelitian, karena berbagai informasi dan inovasi ilmiah hasil penelitian terbaru akan dapat digunakan dan dikembangkan lebih lanjut. Dengan e-journal, artikel hasil penelitian terbaru akan dapat segera dipublikasikan dan dimanfaatkan oleh berbagai pemustaka. Adapun karakteristik e-journal adalah sebagai berikut:

1. Kemudahan akses, pemustaka bisa mengakses tanpa harus datang langsung ke perpustakaan, dan tanpa terbatas jam buka layanan.

2. Hemat, dengan e-journal banyak tersedia gratis di internet, juga menghemat biaya fotokopi, perjalanan yang tidak perlu.

3. Mudah ditelusur, e-journal berbentuk file yang umumnya telah terindeks di dalam database maupun terindeks oleh google. 


\title{
KETERPAKAIAN DATABASE ONLINE: STUDI KASUS LAYANAN E-JOURNAL 2007-2010 DI PERPUSTAKAAN UGM
}

\author{
Oleh: Maryono
}

\section{Abstract}

The usage statistics of online databases need to be studied from various aspects, all of which are useful for optimizing the use of the e-journal. This case study examines the ejournal service statistics 2007-2010, as well as its usage growth through the use of booking service of ejournal article at Gadjah Mada University Library. Ebsco is an online database of the most needed, followed by Proquest, JSTOR, Springer, and ScienceDirect. Also found that most users ordering ejournal prefer to come straight away, although it's provided messaging and e-mail services.

Keywords: e-journal, ebsco, proquest, sciencedirect, springer, library statistics

*) Pustakawan UGM

\section{LATAR BELAKANG}

- Penyediaan literatur e-journal melalui database online mengalami pertumbuhan sangat pesat seiring dengan kemudahan akses melalui inovasi teknologi yang diterapkan. Perguruan tinggi pada umumnya telah mulai merintis penggunaan e-journal dengan melanggan sesuai kebutuhan program studi yang diselenggarakan. Ketersediaan free $e$ journal di internet kini juga menjadi sumber literatur e-journal yang sangat besar. Meskipun telah banyak terjadi peralihan dari bentuk tercetak ke bentuk elektronik yang memiliki banyak fitur kemudahan, tetapi ternyata pemakaian jurnal dan e-journal masih sangat rendah atau belum sesuai dengan yang diharapkan. Penelitian oleh Purnomowati (2001 : 10) dan Andriaty (2005:28) membuktikan hal tersebut.

Untuk melanggan database online membutuhkan biaya yang cukup besar. Dengan melanggan database online akan memperoleh hak akses dalam jangka waktu tertentu, tetapi tidak mempunyai hak memiliki secara fisik. Persoalan kepemilikan sering dipermasalahkan. Demikian juga kesesuaian antara biaya dan keterpakaiannya sering dipertanyakan. Oleh karena itu diperlukan kesadaran akan manfaat e-journal yang pada saatnya nanti akan menumbuhkan minat untuk memakai literatur artikel e-journal.

\section{A. Rumusan Masalah}

1. Bagaimanakah pertumbuhan pemakaian layanan e-journal?

2. Bagaimanakah pertumbuhan komposisi pemakai layanan e-journal?

3. Bagaimanakah pertumbuhan penggunaan media pemesanan $e$ journal?

4. Bagaimanakah pertumbuhan jumlah $e$ journal yang dipesan dan belum tersedia?

5. Bagaimanakah pertumbuhan pemakai masing-masing database e-journal?

\section{B. Tujuan Penelitian}

1. Untuk mengetahui pertumbuhan pemakaian layanan e-journal

2. Untuk mengetahui pertumbuhan komposisi pemakai layanan e-journal

3. Untuk mengetahui pertumbuhan penggunaan media pemesanan $e$ journal

4. Untuk mengetahui pertumbuhan jumlah e-journal yang dipesan dan belum tersedia

5. Untuk mengetahui pertumbuhan pemakai masing-masing database ejournal 
4. Kecepatan terbit, artikel e-journal terbit lebih cepat dari versi cetaknya.

5. Interaktif, e-journal memiliki karakter interaktif yang membuatnya mudảh berkomunikasi ilmiah dengan sesama masyarakat profesi, artikel baru bisa langsung dibaca, cepat ditanggapi, dan berdiskusi dengan penulisnya.

6. Fitur layanan, karena e-journal berbentuk file, berbagai fitur layanan bisa disediakan, di antaranya links yang menyediakan informasi tambahan ke artikel atau alamat website tertentu. Fitur lainnya yaitu related articles, menyediakan informasi artikel terkait dengan artikel yang sedang dibaca.

7. Portabel, e-journal mudah dibawa dalam jumlah besar dengan flashdisk.

8. Animasi, dengan e-journal bisa disediakan file pendukung artikel, berupa animasi, ataupun film.

9. Kepemilikan, pada umumnya pemahaman melanggan jurnal adalah memilikinya setèlah membayar biaya berlangganan.

Sedangkan berlangganan e-journal umumnya tidak disertakan bentuk fisiknya , jadi hanya sekedar mengakses dan mengunduh artikel lengkap sesuai kebutuhan, bukan memilikinya.

\section{METODOLOGI PENELITIAN}

Pemakaian e-journal dapat diukur menggunakan data statistik dari masing-masing penerbit database e-journal untuk mendapatkan informasi di antaranya jumlah pengakses, jumlah artikel yang diunduh, serta jumlah penelusuran. Cara lainnya yaitu dengan melakukan analisis sitiran terhadap literatur yang disitir dalam karya tulis dalam bidang ataupun kelompok tertentu. Dengan analisis sitiran bisa didapatkan informasi literatur yang paling sering disitir, jumlah artikel yang dihasilkan oleh tiap penulis, serta usia literatur yang disitir. Dalam penelitian ini pemakaian ejournal diukur dari statistik layanan e-journal UPT Perpustakaan UGM 2007-2010 yang mendata berbagai aspek pemesanan artikel ejournal.

\section{PEMBAHASAN}

Beberapa aspek layanan ejournal 20072010 berhasil didata, di antaranya tabel 1 jumlah pemesanan, tabel 2 asal pemesan, tabel 3 media pemesanan, tabel 4 jumlah jurnal belum tersedia, serta tabel 5 asal literatur jurnal didapat.

Tabel 1 Jumlah Pemesanan Literatur Jurnal

\begin{tabular}{|c|c|}
\hline Tahun & Jumlah Pemesanan \\
\hline 2007 & 32 \\
\hline 2008 & 330 \\
\hline 2009 & 431 \\
\hline 2010 & 570 \\
\hline
\end{tabular}

Sumber Data Primer yang diolah, 2012

Tabel 1 menunjukkan bahwa keterpakaian jasa layanan penelusuran e-journal semakin meningkat. Hal ini mengindikasikan bahwa terdapat relevansi antara koleksi $e$ journal yang dilanggan dengan literatur yang dibutuhkan sivitas untuk mendukung berbagai program riset dan pendidikan yang ada. Pertumbuhan pesat tersebut dimungkinkan sebagai hasil dari kegiatan sosialisasi database e-journal yang gencar dilaksanakan beberapa tahun terakhir. Tetapi juga dapat diindikasikan bahwa banyak pemustaka, sivitas UGM maupun non-UGM belum mampu mendapatkan literatur artikel dengan efektif, atau dengan kata lain masih rendah literasi informasinya, sehingga merasa perlu untuk memakai layanan pemesanan ejournal.

Tabel 2 Jumlah Pemesan Berdasarkan Asal

\begin{tabular}{|c|c|c|}
\hline Tahun & UGM & Non-UGM \\
\hline 2007 & 14 & 18 \\
\hline 2008 & 158 & 172 \\
\hline 2009 & 238 & 193 \\
\hline 2010 & 307 & 263 \\
\hline
\end{tabular}

Sumber Data Primer yang diolah, 2012

Tabel 2 di atas menunjukkan bahwa pemakai jasa layanan penelusuran e-journal, bukan hanya berasal dari sivitas akademika UGM, tetapi juga masyarakat luas, dengan jumlah yang cukup berimbang. Hal ini juga berarti bahwa penyediaan koleksi database online telah memberi manfaat, tidak hanya bagi sivitas UGM tetapi juga masyarakat sekitarnya. 
Tabel 3 Media yang digunakan untuk memesan literatur jurnal

\begin{tabular}{|l|c|c|c|}
\hline Tahun & Langsung & SMS & Email \\
\hline 2007 & 32 & & \\
\hline 2008 & 323 & 7 & \\
\hline 2009 & 428 & 1 & 2 \\
\hline 2010 & 542 & 26 & 2 \\
\hline
\end{tabular}

Sumber Data Primer yang diolah, 2012

Tabel 3 di atas menunjukkan bahwa, pemakai jasa layanan penelusuran e-journal pada umumnya lebih menyukai datang langsung untuk memesan artikel. Kemungkinan karena mereka tidak suka atau gagap teknologi seluler dan e-mail, tetapi lebih karena keinginan untuk berdiskusi secara langsung dengan pustakawan, merinci topik yang dibutuhkan, menuliskan nama latin atau deskriptor berupa istilah dalam bahasa Inggris yang lazim dipakai dalam bidang ilmu masing-masing.

Tabel 4 Jumlah Jurnal Dipesan yang Belum Tersedia

\begin{tabular}{|c|c|}
\hline Tahun & Jumlah \\
\hline 2007 & 2 \\
\hline 2008 & 22 \\
\hline 2009 & 50 \\
\hline 2010 & 113 \\
\hline
\end{tabular}

Sumber Data Primer yang diolah, 2012

Tabel 4 menunjukkan bahwa terdapat beberapa jurnal yang dibutuhkan pemakai, tetapi belum tercakup di dalam database ejournal yang dilanggan, sehingga beberapa di antara mereka harus membayar mahal untuk membelinya. Meskipun jumlah database dan $e$ journal yang dilanggan telah bertambah secara signifikan, ternyata masih ada beberapa judul yang belum tersedia, dengan jumlah yang cukup memadai.

Tabel 5 Jumlah Pemesanan yang Didapat Melalui Berbagai Database

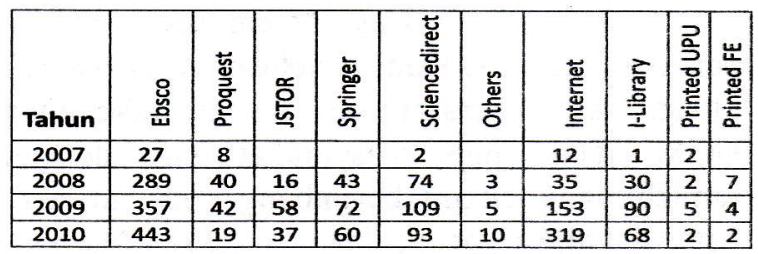

Sumber Data Primer yang diolah, 2012
Tabel 5 menunjukkan bahwa Ebsco masih tetap menjadi sumber utama yang diandalkan untuk mendapatkan artikel $e$ journal. Meskipun jumlah database yang dilanggan sudah mencapai sekitar 25 database, dan masing-masing terdiri dari ribuan judul $e$ journal. Ebsco masih menjadi sumber utama, karena e-journal yang dikelola Ebsco mencakup subyek-subyek yang banyak dibutuhkan sivitas. Penelitian sebelumnya oleh Maryono (2010:26), dikemukakan bahwa subyek ilmu psikologi, ilmu akuntansi, ilmu manajemen, ilmu ekonomi, ilmu medis, teknologi, industri dan ilmu pertanian merupakan subyek-subyek dengan jumlah pemesan terbanyak. Subyeksubyek ilmu tersebut tercakup dalam database Ebsco melalui Academic Source, Business Source, MEDLINE, serta SocINDEX. Berdasarkan data tabel 5 di atas juga ditemukan bahwa sangat sedikit artikel relevan yang bisa didapatkan dari jurnal tercetak, yaitu kurang dari $1 \%$, dan dari sejumlah kecil tersebut terutama adalah jurnal lokal berbahasa Indonesia. Sedangkan internet merupakan sumber artikel ejournal yang sangat besar, karena telah banyak dirintis gerakan open access dan free ejournals untuk berbagai bidang studi.

Dalam hal penggunaan media seluler (SMS) dan email untuk melayani pemesanan $e$ journal, memang masih terdapat kendala:

1. Kendala menggunakan SMS, seringkali teks terputus, karena umumnya penulisan topik harus spesifik dan kompleks serta panjang, menyebabkan tidak sempurnanya informasi topik dan data sitasi yang dibutuhkan.

2. Kendala menggunakan email, akses internet melambat secara drastis pada jam kerja siang hari, menyebabkan tertundanya pemesanan dan pengiriman artikel. Sedangkan jika menggunakan media chatting, facebook, serta twitter terkendala oleh melambatnya akses internet dan belum populernya identitas e-mail pustakawan jurnal.

Dengan berbagai kendala tersebut, sebagian besar pemakai layanan pemesanan $e$ journal harus datang langsung untuk memesan 
artikel, padahal semestinya dengan karakter $e$ journal yang mudah diakses dari manapun, mudah ditelusur, mudah dibawa, mudah diterbitkan, mudah disebarkan, mudah dikirim, mudah mengedit, mudah menghemat, mudah berkomunikasi ilmiah dan serba mudah, pemustaka tidak perlu datang langsung hanya untuk memesan artikel.

Permasalahan lain yang sering muncul adalah sebagai berikut:

1. Kepemilikan e-journal, karena besarnya biaya berlangganan.

2. Dalam proses mengunduh untuk mendapatkan artikel lengkap, juga sering terjadi masalah karena diantara pemakai kemungkinan ada yang menggunakan program robot mengunduh artikel secara masif, dalam jumlah besar sekaligus. Program ini mengakibatkan server hang, dan akses e-journal dicabut. Bagi pustakawan jurnal, menyiasati hal ini dengan hanya mengunduh sesuai topik spesiifik yang dipesan saja, bukan keseluruhan isi database. Artikel yang telah diunduh bisa ditampung dalam hardisk yang kini harganya mulai merakyat, dan bisa dipakai lagi di kemudian hari.

\section{KESIMPULAN}

Pemakaian database online dapat diukur dari statistik penggunaan jasa pemesanan artikel, meskipun data tersebut hanya merupakan data parsial, tidak mencakup pengakses keseluruhan. Pemakai layanan pemesanan e-journal tumbuh sangat pesat, dengan jumlah yang berimbang antara sivitas dan non-sivitas UGM. Pemakai layanan pemesanan e-journal sebagian besar masih datang langsung ke perpustakaan UGM, meskipun telah tersedia jaringan internet dan teknologi seluler. Sedangkan Ebsco menjadi sumber artikel e-journal yang utama, meskipun sekarang telah dilanggan sebanyak kurang lebih 25 database e-journal.

\section{SARAN}

Penelitian lanjutan untuk mengukur pemakaian ejournal dan menjelaskan berbagai fakta dalam penelitian ini sangat penting dilanjutkan, yang tentunya sangat bermanfaat bagi kepustakawanan mengingat koleksi $e$ journal merupakan jenis media koleksi yang sedang bertumbuh dengan pesat. Di samping itu penyediaan prasarana untuk mengakses $e$ journal, perlu juga ditingkatkan dengan rutin memperbaruinya mengingat pentingnya mendukung kinerja layanan dengan teknologi yang sesuai. Dalam hal kinerja pustakawan jurnal, penting juga meningkatkan komunikasi interaktif dengan masyarakat pemustaka, khususnya memakai layanan internet, karena berdasarkan fakta sebagian besar pemesanan $e$ journal datang langsung, menunjukkan belum optimalnya pemanfaatan karakter e-journal yang mudah diakses dan mudah berkomunikasi ilmiah. Dengan mempertimbangkan tingginya jumlah pemustaka yang menggunakan jasa pemesanan e-journal dari beberapa database tertentu, sebaiknya 5 database online utama yaitu Ebsco, Proquest, JSTOR, Springer dan Sciencedirect tetap dilanggan di masa mendatang.

\section{DAFTAR PUSTAKA}

Ali, P.M. Naushad dan Faizul Nisha. 2011. Use of ejournals among research scholars at Central Science Library, University of Delhi. Collection Building.Volume 30, Number 1, pp. 53-60

Andriaty, Etty. 2005. Pemanfaatan Jurnal Elektronis Dan Kemutakhiran Informasi Yang Disitir Dalam Publikasi Primer. Jurnal Perpustakaan Pertanian Vol. 14, Nomor 2, hlm.25-31

Ilo, Promise Ifeoma dkk. 2010. Impact of the Internet on Final Year Students' Research: A Case Study of Covenant University, Ota, Nigeria. Library Philosophy and Practice, July, pp.1-7

Kusmayadi, Eka dan Rushendi. 2007. Ketersediaan Informasi Bagi Peneliti: Studi Kasus Perpustakaan Balai Penelitian Tanaman Obat dan Aromatik. Jurnal Perpustakaan Pertanian, 16(2):1

Maryono. 2010. Subyek Artikel Dipesan Dan Kesesuaiannya Dengan Klaster Riset. 
Berkala Ilmu Perpustakaan dan Informasi, Vol VI (1), hlm. 23-27

Perpustakaan Perguruan Tinggi: Buku . Pedoman, edisi ketiga. 2005. Jakarta: Departemen Pendidikan Nasional RI

Prawati, Budi. 2003. Keterpakaian koleksi majalah ilmiah Pusat Perpustakaan dan Penyebaran Teknologi Pertanian Oleh Peneliti Badan Litbang Pertanian. Jurnal Perpustakaan Pertanian, 12(1) : 1

Purnomowati, Sri. 2001. Pola Kepengarangan dan Pola Sitiran Dalam Buletin Perpustakaan IKIP Yogyakarta (BPIY) tahun 1995 - 1999. Papirus, 30 (30 (1) : 4-11 